2015; the achieving Priorities of Care (aPoC) document. This audit focused upon the standard of the completion of this document.

Methods Documentation was audited, to review standard of completion, for patients in whom the aPoC document was used between $1 / 7 / 15$ and 30/9/15. During this time there were seven deaths where the aPoC document was used. Staff questionnaires regarding the priorities of care and the aPoC document were also carried out.

Results The desired standard of 100\% completion was used. $43 \%$ of documents were signed by the Consultant deciding to use the aPoC with $29 \%$ of cases having clear documentation that $\mathrm{aPoC}$ was to be used in the medical notes. On average, the standard of completion of the front page was $60 \%$, the recognition of dying section was $61 \%$, previous wishes of the patient $49 \%$, individualised care plan $86 \%$, ongoing medical review $84 \%$ and psychological review 42\%. Staff questionnaires showed that $40 \%$ of staff were not aware of the five priorities of care and $28 \%$ were not aware of the aPoC document.

Conclusions Overall, the standard of completion of the document was variable. Some sections were carried out well but others showed significant areas for improvement. Staff questionnaire data suggests that across different staff groups, there is limited knowledge and awareness of the priorities of care. Staff education will therefore be the main implementation strategy prior to a re-audit of the standard of completion of the apoc document.

\section{P-16 AUDIT OF ADHERENCE TO PRESCRIBING STANDARDS AS A MEANS OF IMPROVING PRESCRIBING PRACTICE ON DRUG CHARTS IN A HOSPICE IN-PATIENT UNIT}

Annelise Matthews, Nick Green, Sunil Hathi, Hamna Jaffar, Arjun Kingdon, Sayyada Mawji. Sue Ryder St. John's Hospice, Moggerhanger, UK

\subsection{6/bmjspcare-2017-00133.16}

Background The safe and effective function of any in-patient unit depends on drug charts being clearly and correctly completed.

Aims To assess the adherence of the medical team to good prescribing practices regarding completion of drug charts. To explore whether audit of this area as part of the junior doctor induction programme provides a means to improve prescribing documentation habits.

Methods The audit tool analysed compliance with standards established by the Sue Ryder Management of Medicines Policy for Care Centres and Hospices (July 2014). Junior doctors analysed the notes and drug charts of 10 in-patients sampled at random. Performance of the entire medical team was audited at the beginning and end of 2 successive junior doctor placements.

Standards Audited fields were

- Patient Identifiers.

- Chart completion: eg, capitals; generic names.

- Rewriting

- Technical information: eg, correct use of units, decimals etc.

- Prescriptions written correctly: eg, signed, dated, PRN indications etc.

The standard set for all criteria was 100\%.
Results Each audit fell significantly short of the desired standard of $100 \%$ in the 26 possible criteria. Both audit cycles demonstrated improvement in prescribing performance. Between December 2014 and February 2015, 100\% concordance rose from $32 \%(8 / 25)$ to $50 \%(11 / 22)$ of assessed criteria, with betterment seen in another $73 \%$ (8/11). Comparison of April 2015 and July 2015 saw 100\% concordance increase from $28 \%(5 / 23)$ to $69 \%(18 / 26)$ with progression in a further $40 \%(2 / 5)$ of criteria.

Discussion and conclusion Reflecting on the data, it was clear that those who had been auditors became better prescribers. Most of the remaining errors were made by consultants and registrars! This project suggests that involving junior doctors in prescribing audits is effective at educating them in good prescribing practice. Perhaps senior doctors would also benefit from engaging in such an exercise?

\section{P-17 IMPROVING PSYCHOLOGICAL ASSESSMENT OF HOSPICE IN-PATIENTS USING OACC}

Annelise Matthews, Hannah Huang. Sue Ryder St John's Hospice, Moggerhanger, UK

\subsection{6/bmjspcare-2017-00133.17}

Background Anxiety and depression are under-diagnosed and under-treated in palliative care with prevalence thought to be 20\%-49\%. The Palliative Adult Network Guidelines state that psychological assessment is imperative to guide management. The Outcome Assessment and Complexity Collaborative (OACC) is seeking to implement outcome measures into routine palliative care that may improve practice.

Aim To review whether psychological symptoms including mood state and anxiety were being assessed and reviewed in patients admitted to St John's Hospice, Moggerhanger, UK.

Method Data were collected from 28 patients admitted to St John's Hospice during August 2015. Psychological assessment recorded in their medical notes were systematically reviewed using a checklist devised from OACC.

The medical clerking was then changed in line with OACC so the psychological assessment included two questions taken from Integrated Palliative care Outcome Scale:

- Over the past 3 days, have you been feeling anxious or worried about your illness or treatment?

- Have you been feeling depressed?

A separate assessment of Information and Insight was also introduced.

All case notes were re-audited in November 2015.

Results $80 \%$ of patients had a psychological assessment completed by a doctor but only 35\% mentioned mood or anxiety. Most common non-mood or anxiety related comments related to physical symptoms, prognosis or insight.

At re-audit, $100 \%$ of patients had a medical psychological assessment and there was a significant decrease in recording of non-mood symptoms.

Conclusions Without clear prompts, doctors often made poor assessments focusing on non-mood symptoms like insight or prognosis. Implementing OACC caused significant improvements in psychological assessment of patients by doctors. The change required minimal training. OACC can be a powerful and measurable tool for improving patient assessment. 